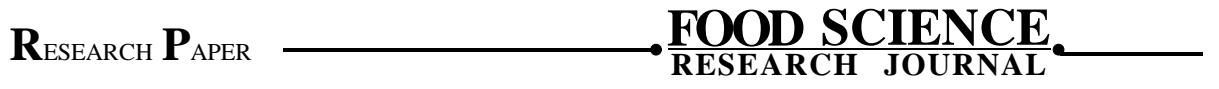
e ISSN-2230-9403 - Visit us : www. researchjournal.co.in Volume 9 | Issue 1 | April, 2018 | 38-41 DOI : $10.15740 / \mathrm{HAS} / \mathrm{FSRJ} / 9.1 / 38-41$

\title{
Impact of nutrition education programmes on pregnant and lactating women in Sultanpur district
}

\author{
Kiran Agrahari and $V_{\text {andana }} \mathrm{Y}_{\text {adav }}$
}

\begin{abstract}
Nutrition education is any combination of educational strategies, accompanied by environmental supports, designed to facilitate voluntary adoption of food choices and other food- and nutrition-related behaviours conducive to health and well-being. Nutrition education is delivered through multiple venues and involves activities at the individual, community, and policy levels Nutrition education is a mechanism to enhance awareness, as a means to self-efficacy, surrounding the trigger of healthy behaviour Nutrition education programmes endeavour to improve participants' dietary intakes during pregnancy by promoting balanced diet. Since the demands for specific nutrients during pregnancy and lactation are directly depend on a mother's intake. Suboptimal level of these crucial nutrients during pregnancy may increase the risk of adverse pregnancy outcomes such as neural tube defects, early fatal loss, preeclampsia, low birth weight and maternal mortality. Although poor dietary intake is a common cause of micronutrient deficiencies, the root cause is linked with low socioeconomic status and lack of knowledge about healthy eating patterns. This study was performed to determine the impact of nutrition education programmes on pregnant and lactating women in Sultanpur district. For the research survey method was used for the collection of data. Result show that maximum women were positive impact of nutrition education programmes.
\end{abstract}

Key Words : Overwhelming, Intervention, Trigger, Maternal, Mortality

How to cite this article : Agrahari, Kiran and Yadav, Vandana (2018). Impact of nutrition education programmes on pregnant and lactating women in Sultanpur district. Food Sci. Res. J., 9(1): 38-41, DOI : 10.15740/HAS/FSRJ/9.1/38-41.

\footnotetext{
Author for correspondence :

Vandana Yadav, Kamla Nehru Institute of Physical and Social Science,

Sultanpur (U.P.) India

(Email : vand.yd923@gmail.com)

Associate Authors' :

Kiran Agrahari, Kamla Nehru Institute of Physical and Social Science,

Sultanpur (U.P.) India
} 